Research Article

\title{
Stator Current Vector Orientation-Based Backstepping Predictive Control of Torque Ripple Minimization for PMSM with consideration of Electrical Loss
}

\author{
Yang Yu $\mathbb{D},{ }^{1,2}$ Leyao Cong, ${ }^{1}$ Xia Tian, ${ }^{1}$ Renjie Xie, ${ }^{1}$ and Jianbin Lu ${ }^{1}$ \\ ${ }^{1}$ State Key Laboratory of Alternate Electrical Power System with Renewable Energy Sources, \\ North China Electric Power University, Baoding 071003, China \\ ${ }^{2}$ Hebei Key Laboratory of Distributed Energy Storage and Micro Grid, North China Electric Power University, \\ Baoding 071003, China \\ Correspondence should be addressed to Yang Yu; ncepu_yy@163.com
}

Received 5 January 2020; Accepted 12 March 2020; Published 19 May 2020

Academic Editor: Denizar Cruz Martins

Copyright ( $\odot 2020$ Yang Yu et al. This is an open access article distributed under the Creative Commons Attribution License, which permits unrestricted use, distribution, and reproduction in any medium, provided the original work is properly cited.

\begin{abstract}
Existing research studies on torque ripple suppression mostly ignore the electrical loss of PMSM. However, the electrical loss will not only decrease the operating efficiency but also adversely influence the suppression of torque ripple. This paper attempts to construct a unified framework to suppress torque ripple with consideration of electrical loss. Firstly, a dynamic mathematical model of PMSM under current vector orientation is established with a combination of electrical loss. The constraints that can achieve the control of both torque ripple and electrical loss for PMSM are derived. Then, on the basis of the backstepping control principle, a closed-loop $I / f$ integrative control method under stator current vector orientation is proposed. Meanwhile, this paper also proposes a speed estimation algorithm of PMSM based on the least-squares method to realize wide-range speed identification and an online prediction algorithm for control parameters of backstepping control to enhance the stability of the motor in operation. Both simulations and experiments have been performed to verify the effectiveness of the proposed control method, and the results indicate that torque ripple is suppressed effectively, operating efficiency is significantly improved, and all variables are regulated to track their reference signals correctly and rapidly.
\end{abstract}

\section{Introduction}

Permanent magnet synchronous motor (PMSM) is broadly used in various industrial fields for its advantages of simple structure, good dynamic response, and high-power factor [1]. However, for reasons like asymmetric winding structure and flux harmonics produced by the permanent magnet, torque ripple is a crucial problem of PMSM that would lead to speed fluctuation and weaken dynamic performance during operation [2]. Meanwhile, the operating efficiency of PMSM is another issue that deserves more and more attention to energy-saving $[3,4]$. If the damping windings are ignored, the loss of PMSM is comprised of electrical and mechanical losses, where electrical loss includes iron loss and copper loss as well. The control of the motor's loss will improve its operating efficiency. Therefore, simultaneous completions of suppressing torque ripple and reducing operating efficiency have dual beneficial effects on overall drive performance of PMSM.

For the suppression of torque ripple in PMSM, the approaches can be mostly classified into two categories: structure of motor ontology optimized to produce air-gap field more closely to sinusoidal and decrease cogging torque [5-7] and appropriate control strategies devised to smooth electromagnetic torque [8-13]. The second kind of method is more suitable for motors in service. The iterative learning control strategy is adopted in $[8,9]$; the system regulates the current components continuously to achieve the suppression of torque ripple based on previous information. However, this control method is difficult to provide a suitable error compensation signal under the condition of variable speed. Meanwhile, there are multiple PI controllers 
in [9] that need to be adjusted, which requires a relatively large calculation amount. A current compensation method is proposed in [10], and a rotor flux observer based on Kalman filter is designed to suppress torque ripple to some extent. But the performance of the Kalman filter depends greatly on the parameters of the motor, which makes the proposed method to be less robust. Other compensation methods are investigated in [11-13], but these methods have compensation errors more or less, and their applications are sometimes limited.

Above all, existing research on torque ripple suppression often disregards electrical loss. In reality, these two problems are interacting with each other, and ignoring electrical loss will not only decrease the operating efficiency of PMSM but also bring some unfavorable influence on the overall control scenario. As for the operating efficiency of a motor, it is determined by the control of its loss. When a PMSM runs stably at a certain speed, its mechanical loss could hardly be reduced since it is mostly restricted by the speed. Moreover, the mechanical loss is only a small proportion of a total loss. Therefore, the key point of the loss control is to focus on reducing electrical loss, which means lower iron and copper losses. Control strategies used to realize a minimum electrical loss in recent years are commonly divided into two types of online search-based minimum power control $[14,15]$ and loss-based model control [16-18]. The former is used for steady-state operation. But this method has a high requirement of the accuracy in detecting input power and normally takes a long time to converge. Now, it is gradually taken place by the latter method. The latter establishes an accurate loss model of the motor and achieves optimal operation by analyzing the relationship of various losses to exciting current and speed. This method has a fast response speed and is suitable for variable speed operation. The variation of the inductance during operation is considered in [16], and the approximately linear optimal current equation is derived based on Kuhn-Tucker theory. In terms of loss equation, the optimal output voltage by using the Lyapunov stability theory is obtained in [17]. However, the whole schemes of the above two control methods are complicated. The approximate approach is used in [18] to find the optimal solution, which reduces the calculation amount but also weakens the calculation accuracy.

Hence, this paper attempts to construct a unified control method to realize torque ripple suppression with consideration of electrical loss. Nowadays, $I / f$ control is used in the startup for sensor-less PMSM drives [19]. However, from the viewpoint of the control structure, conventional $I / f$ control is an open-loop control strategy that exhibits the problem of stability and will consume more energy with fixed current amplitude. Hence, this paper will make a significant contribution to the existing I/ $f$ control method and introduce an improved method as the closed-loop control framework.

Through the integration of torque ripple suppression with electrical loss reduction, an overall dynamic mathematical model of PMSM under closed-loop I/f control framework is constructed and various constraints are derived to inhibit torque ripple and pursuit optimal operating efficiency simultaneously. A backstepping control-based closed-loop $I / f$ integrative controller is proposed to suppress torque ripple and reduce electrical loss instantaneously with a combination of the least-square-based speed estimation algorithm. Meanwhile, a nonlinear predictive control algorithm is introduced to adjust multiple control parameters online, which improves the control precision and enhances the stability of the proposed control scheme. Simulations and hardware experiments have demonstrated the feasibility and practicability of the proposed controller. The results display that both steady-state and dynamic performances are improved, and torque ripple in PMSM is suppressed effectively while operating efficiency is also enhanced.

The following context is arranged as follows: an overall mathematical model of the system is described in Section 2. The control algorithm of torque ripple suppression with consideration of the electrical loss for PMSM is proposed in Section 3. The method of speed identification is designed in Section 4. The online prediction algorithm for control parameters is designed in Section 5. The simulation and experimental analysis are conducted in Section 6. The last section summarizes the research results.

\section{Modeling of the Overall System}

2.1. Constraint Condition under Minimum Loss Operation for PMSM. The equivalent circuits of PMSM in $d-q$ axis including iron loss resistance are plotted in Figure 1 and corresponding dynamic equations can be expressed in the following equation:

$$
\left\{R_{c} i_{c d}=-n_{p} \omega_{r} L_{q} i_{w q}, R_{c} i_{c q}=n_{p} \omega_{r}\left(\lambda_{r}+L_{d} i_{w d}\right)\right\},
$$

where $i_{w d}$ and $i_{w q}$ are the active current components in $d$ and $q$ axes, $i_{c d}$ and $i_{c q}$ are the iron loss current components in $d$ and $q$ axes, $L_{d}$ and $L_{q}$ are the inductors in $d$ and $q$ axes, $u_{s d}$ and $u_{s q}$ are the voltages in $d$ and $q$ axes, $R_{c}$ is the equivalent iron loss resistance, $n_{p}$ is the number of pole pairs of rotor, $\lambda_{r}$ is the linkage of permanent magnets, and $\omega_{r}$ is the mechanical angular velocity of the rotor.

The effective electromagnetic torque $T_{e}$ is written as

$$
T_{e}=\left(\frac{3 n_{p} \lambda_{r} i_{w q}}{2}\right) \text {. }
$$

The total electrical loss $P_{\text {Loss }}$ including copper loss $P_{\mathrm{Cu}}$ and iron loss $P_{\mathrm{Fe}}$ of PMSM are described as follows:

$$
\left\{\begin{array}{l}
P_{\mathrm{Loss}}=P_{\mathrm{Cu}}+P_{\mathrm{Fe}}, \\
P_{\mathrm{Fe}}=\left(\frac{3 R_{c}\left(i_{c d}^{2}+i_{c q}^{2}\right)}{2}\right), \\
P_{\mathrm{Cu}}=\left(\frac{3 R_{s}\left[\left(i_{c d}+i_{w d}\right)^{2}+\left(i_{c q}+i_{w q}\right)^{2}\right]}{2}\right) .
\end{array}\right.
$$

In terms of electromagnetic torque $T_{\mathrm{e}}$ in equation (2), $i_{w q}$ can be acquired. By a partial derivative of $P_{\text {Loss }}$ in equation 


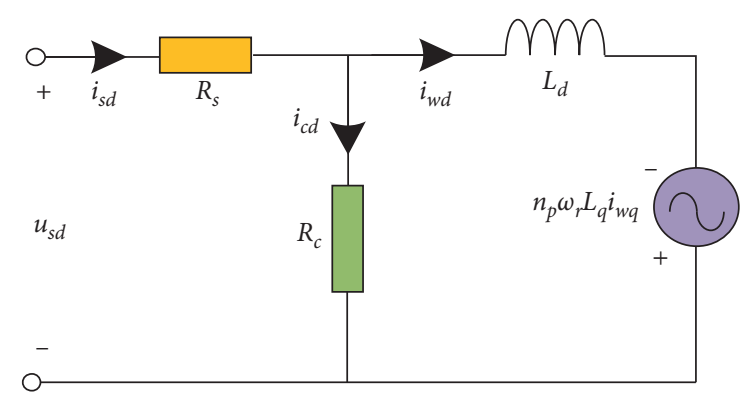

(a)

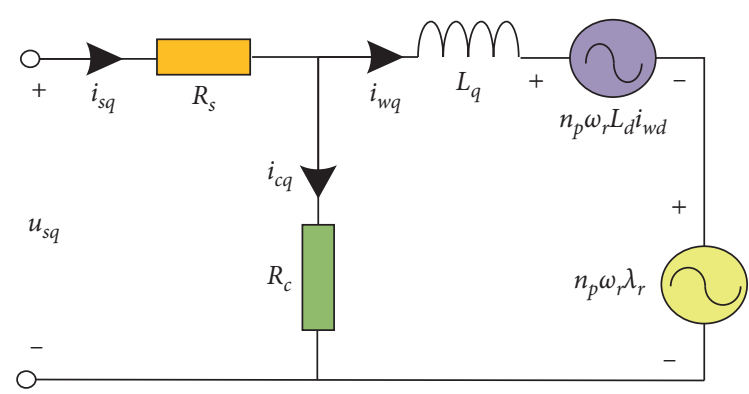

(b)

Figure 1: Equivalent circuit of PMSM in (a) $d$-axis and (b) $q$-axis.

(3) with respect to $i_{w d}$, optimal stator current to achieve minimum total loss is given by

$$
i_{w d r e f}=-\frac{\left(n_{p}^{2} \omega_{r}^{2} L_{d}\left(R_{s}+R_{c}\right) \lambda_{r}\right)}{\left(R_{s} R_{c}^{2}+n_{p}^{2} \omega_{r}^{2} L_{d}^{2}\left(R_{s}+R_{c}\right)\right)} .
$$

Combined with equation (1), the constraint condition of $d$-axis current in PMSM under minimum totalloss is

$$
i_{\text {dref }}=-\frac{n_{p}^{2} \omega_{r}^{2} \lambda_{r} L_{d} R_{c}}{R_{s} R_{c}^{2}+n_{p}^{2} \omega_{r}^{2} L_{d}^{2}\left(R_{s}+R_{c}\right)}-\frac{n_{p} \omega_{r} L_{q} i_{w q}}{R_{c}} .
$$

\subsection{Stator Current Vector Orientation-Based Overall Model of} PMSM. The originally rotating coordinate frame of PMSM is supposed to be $d q o$. Another rotating coordinate frame $d * q * o$ shown in Figure 2 is established to express stator current vector $\mathbf{i}_{s}$, where $d^{*}$ and $q^{*}$ axes indicate the new real and imaginary axes individually, and $\theta_{L}$ is used to represent the angle between $d$ axis and $q^{*}$ axis.

For PMSM, its dynamic equations of stator winding between voltage and current in $d * q * o$ are described as [20]

$$
\begin{aligned}
& u_{s d *}=R_{s} i_{s d *}+\dot{\lambda}_{s d *}-n_{p} \omega_{i} \lambda_{s q *}, \\
& u_{s q *}=R_{s} i_{s q *}+\dot{\lambda}_{s q *}+n_{p} \omega_{i} \lambda_{s d *},
\end{aligned}
$$

where $u_{s d *}$ and $u_{s q *}$ are the voltages in $d^{*}$ and $q^{*}$ axes, $i_{s d *}$ and $i_{s q *}$ are the currents in $d^{*}$ and $q^{*}$ axes, $\lambda_{s d *}$ and $\lambda_{s q *}$ are the flux linkages in $d^{*}$ and $q^{*}$ axes, and $\omega_{i}$ is the rotating speed in $d^{*} q^{*} o$ frame.

In Figure 2, the stator current $i_{s}$ is oriented along $q^{*}$ axis, which makes $i_{s q *}$ to be equal to $i_{s}$ and $i_{s d *}$ to be limited to zero. Furthermore, equations (6) and (7) can be rearranged as

$$
\begin{aligned}
& u_{s d *}=-L_{q *} i_{s} \dot{\theta}_{L}-n_{p} \lambda_{r} \omega_{r} \cos \theta_{L}-n_{p} \omega_{r} L_{q *} i_{s}, \\
& u_{s q *}=R_{s} i_{s}+L_{q *} \dot{i}_{s}+n_{p} \lambda_{r} \omega_{r} \sin \theta_{L},
\end{aligned}
$$

where $L_{d *}$ is the inductor in $d^{*}$ axis and $L_{q *}$ is the inductor in $q^{*}$ axis.

Additionally, the relation of $\theta_{L}$ among $\omega_{r}$ and $\omega_{i}$ can be described as follows:

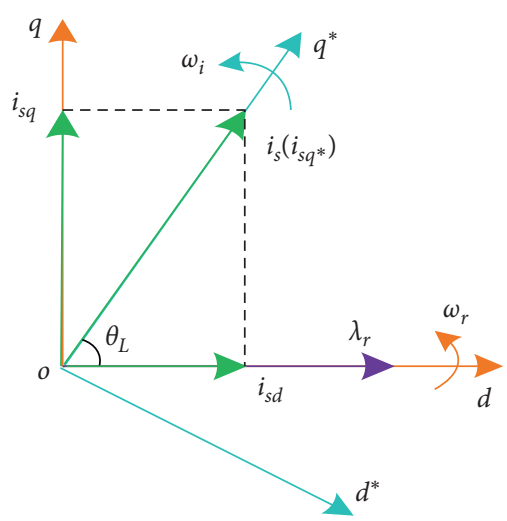

Figure 2: $d * q * o$ coordinate frame convenient to investigate stator current.

$$
\dot{\theta}_{L}=n_{p}\left(\omega_{i}-\omega_{r}\right)
$$

Ultimately, the motion equation of the rotor is shown as

$$
\dot{\omega}_{r}=\left(\frac{\left(T_{e}-T_{L}-B \omega_{r}\right)}{J}\right),
$$

where $T_{L}$ is the load torque, $B$ is the viscous coefficient, and $J$ is the moment of inertia.

The overall dynamical model of PMSM in $d * q * o$ coordinate frame is built from equations (8) to (11). It is worth mentioning that $\theta_{L}$ appears to be restricted to the range of $\left(0^{\circ}, 180^{\circ}\right)$ and a suitable acceleration of the speed should be required in conventional $I / f$ control exhibited to run the motor properly and stably.

2.3. Constraint Condition for Torque Ripple Suppression of $P M S M$. From the perspective of magnetic coenergy, $T_{\mathrm{e}}$ can be expressed as [21]

$$
\begin{aligned}
T_{\mathrm{e}}= & K_{p}\left\{\left(L_{d}-L_{q}\right)\left(i_{s} \cos \theta_{L}\right)\left(i_{s} \sin \theta_{L}\right)+\psi_{d}\left(i_{s} \sin \theta_{L}\right)\right. \\
& -\psi_{q}\left(i_{s} \cos \theta_{L}\right)+\left(i_{s} \cos \theta_{L}\right) p\left(\psi_{d}\right) \\
& \left.+\left(i_{s} \sin \theta_{L}\right) p\left(\psi_{q}\right)\right\}+T_{\operatorname{cog}},
\end{aligned}
$$


where $p$ indicates $\mathrm{d}(\cdot) / \mathrm{d} \theta$ in the article, $K_{p}=3 n_{p} / 2, \psi_{d}$ and $\psi_{q}$ are the flux linkages in $d$ and $q$ axes, and $T_{\operatorname{cog}}$ indicates the cogging torque. And because of

$$
\left\{\begin{array}{l}
i_{s}=i_{s 0}+\sum_{k} I_{s k} \cos \left(k \theta-\phi_{s k}\right), T_{c o g}=\sum_{k} T_{c k} \cos \left(k \theta-\phi_{c k}\right), \\
\psi_{d}=\psi_{0}+\psi_{d h}=\psi_{0}+\sum_{k} \psi_{d k} \cos \left(k \theta-\phi_{\psi k}\right), \\
\psi_{q}=0+\psi_{d h}=0+\sum_{k} \psi_{q k} \sin \left(k \theta-\phi_{\psi k}\right),
\end{array}\right.
$$

where $k$ is the harmonic order, $I_{s k}$ and $\phi_{s k}$ are the $k$ th harmonic current and its phase angle, $\psi_{0}$ is the average magnetic linkage in $d$ axis, $\psi_{d k}$ and $\psi_{q k}$ are the $k$ th harmonic components of permanent magnet flux in $d$ and $q$ axes, $\phi_{\psi k}$ is the $k$ th flux harmonic's phase angle, and $T_{c k}$ and $\phi_{c k}$ are the $k$ th harmonic's magnitude and phase angle in cogging torque.

By substituting equation (13) into equation (12), a more specific expression of $T_{e}$ can be obtained. In reality, $\psi_{d k}, \psi_{q k}$, and $I_{s k}$ are only small proportions in their respective normal values. The product terms among three variables of $\psi_{d k}, \psi_{q k}$, and $I_{s k}$ will be smaller which can be ignored. Hence, the expression of $T_{e}$ can be simplified as

$$
\begin{aligned}
T_{e}= & T_{0}+\sum_{k} \sqrt{\left(C_{k}^{2}+D_{k}^{2}+2 C_{k} D_{k}\right)} \cos \left(k \theta-\phi_{k}\right) \\
& +\sum_{k} \sqrt{E_{k}^{2}+F_{k}^{2}} \cos \left(k \theta-\varphi_{k}\right),
\end{aligned}
$$

where $T_{0}$ is the active component of $T_{e}$ and $\phi_{k}$ and $\varphi_{k}$ are two introduced angles. Considering $L_{d}=L_{q}$ in surface-mounted PMSM,

$$
\left\{\begin{array}{l}
C_{k}=2 K_{p} i_{s 0}\left(L_{d}-L_{q}\right) \cos \theta_{L} \sin \theta_{L} I_{s k}=0, \\
D_{k}=K_{p} I_{s k} \psi_{0} \sin \theta_{L} \\
\tan \varphi_{k}=\left(\frac{F_{k}}{E_{k}}\right) \\
\tan \phi_{k}=\frac{C_{k} \sin \phi_{s k}+D_{k} \sin \phi_{s k}}{C_{k} \cos \phi_{s k}+D_{k} \cos \phi_{s k}}=\tan \phi_{s k}, \\
E_{k}=T_{c k} \cos \phi_{c k}+K_{p} i_{s 0} \sin \theta_{L}\left(\psi_{d k}+k \psi_{q k}\right) \cos \phi_{\psi k} \\
-K_{p} i_{s 0} \cos \theta_{L} \psi_{q k} \cos \phi_{\psi k}-K_{p} i_{s 0} \cos \theta_{L} k \psi_{d k} \sin \phi_{\lambda k} \\
F_{k}=T_{c k} \sin \phi_{c k}+K_{p} i_{s 0} \sin \theta_{L}\left(\psi_{d k}+k \psi_{q k}\right) \sin \phi_{\psi k} \\
+K_{p} i_{s 0} \cos \theta_{L} \psi_{q k} \sin \phi_{\psi k}+K_{p} i_{s 0} \cos \theta_{L} k \psi_{d k} \cos \phi_{\psi k}
\end{array}\right.
$$

If all harmonics in $T_{e}$ can be inhibited, we can get

$$
\sum_{k}\left|D_{k}\right| \cos \left(k \theta-\phi_{k}\right)+\sum_{k} \sqrt{E_{k}^{2}+F_{k}^{2}} \cos \left(k \theta-\varphi_{k}\right)=0 .
$$

Furthermore, for the $k$ th harmonic current in equation (14), it also should be suppressed:

$$
\left|D_{k}\right| \cos \left(k \theta-\phi_{k}\right)+\sqrt{E_{k}^{2}+F_{k}^{2}} \cos \left(k \theta-\varphi_{k}\right)=0 .
$$

Because $\theta_{L}$ is restricted to the range of $\left(0^{\circ}, 180^{\circ}\right), D_{k}$ is supposed to be larger than zero. The optimal angle $\phi_{s k}^{\text {opt }}$ for the $k$ th harmonic current will be determined. Thus,

$$
\left\{D_{k}=\sqrt{E_{k}^{2}+F_{k}^{2}}, \phi_{k}-\varphi_{k}=\pi\right\} \text {. }
$$

In the combination of equations (15) and (18), the optimal harmonic current $I_{s k}$ can be solved as

$$
I_{s k}^{\mathrm{opt}}=\left(\frac{\sqrt{E_{k}^{2}+F_{k}^{2}}}{\left(K_{p} \psi_{0} \sin \theta_{L}\right)}\right) \text {. }
$$

Therefore, equations (5) and (19) constitute constraint conditions for torque ripple minimization with consideration of electrical loss.

\section{Control of Torque Ripple with consideration of Electrical Loss}

In this section, a backstepping controller with optimal current conditions is designed. $e_{\theta}, e_{\theta k}, e_{\omega}, e_{i}$, and $e_{i k}$ indicate the tracking errors of angles $\theta_{L}, \theta_{L k}, \omega_{r}, i_{s 0}$, and $i_{s k}$, where $i_{s 0}$ and $i_{s k}$ are the amplitudes of fundamental current and harmonic current, respectively, and $\theta_{L k}$ is the angle between $d$ axis and harmonic current; $\theta_{L k}^{*}=k \theta_{L}^{*} . \theta_{L}^{*}, \theta_{L k}^{*}, \omega_{r}^{*}, i_{s 0}^{*}$, and $i_{s k}^{*}$ are the expected reference signals of $\theta_{L}, \theta_{L k}, \omega_{r}, i_{s 0}$, and $i_{s k}$, respectively. $i_{s k}^{*}$ equals to $I_{s k}^{\mathrm{opt}}$, derived in equation (19).

The first virtual control variable $\theta_{L}^{*}$ will be devised to regulate the speed and also achieve optimal loss:

$$
\theta_{L}^{*}=\arccos \left(\frac{i_{d r e f}}{i_{s 0}^{*}}\right) .
$$

In accordance with the backstepping control principle and because of $e_{\theta}=\theta_{L}-\theta_{L}^{*}$, the derivative of $e_{\theta}$ can be written as

$$
\dot{e}_{\theta}=\dot{\theta}_{L}-\dot{\theta}_{L}^{*}=n_{p}\left(\omega_{i}-\omega_{r}\right)-\dot{\theta}_{L}^{*} .
$$

Then, the second virtual control variable $\omega_{r}^{*}$ can be acquired as follows:

$$
\omega_{r}^{*}=\frac{\left(n_{p} \omega_{i}-\dot{\theta}_{L}^{*}+k_{\theta} e_{\theta}\right)}{n_{p}},
$$

where $k_{\theta}$ is a pending positive number. By substituting equation (22) into equation (21), equation (21) will be rewritten as

$$
\dot{e}_{\theta}=-k_{\theta} e_{\theta} .
$$


In terms of Figure 2 and equation (2), $T_{e}$ can be rewritten as

$$
T_{e}=3 \frac{n_{p} \lambda_{r}\left(i_{s 0} \sin \theta_{L}-i_{c q}\right)}{2}
$$

Due to $e_{\omega}=\omega_{r}-\omega_{r}^{*}$, the derivative of $e_{\omega}$ could be expressed as

$$
\dot{e}_{\omega}=\dot{\omega}_{r}-\dot{\omega}_{r}^{*}=\frac{\left(T_{e}-T_{L}-B \omega_{r}\right)}{J}-\dot{\omega}_{r}^{*},
$$

Therefore, the third virtual control variable $i_{s 0}^{*}$ can be given by

$$
i_{s 0}^{*}=\frac{J\left(\dot{\omega}_{r}^{*}-k_{\omega} e_{\omega}\right)+T_{L}+B \omega_{r}+3 / 2 n_{p} \lambda_{r} i_{c q}}{3 / 2 n_{p} \lambda_{r} \sin \theta_{L}}
$$

where $k_{\omega}$ is a pending positive number. Then, equation (20) can be more specific by substituting equation (5) and equation (26) into it. In addition, substituting equation (26) into equation (25), we can get

$$
\dot{e}_{\omega}=-k_{\omega} e_{\omega} .
$$

Because of $e_{i}=i_{s 0}-i_{s 0}^{*}$, the derivative of $e_{i}$ can be expressed as

$$
\dot{e}_{i}=\dot{i}_{s 0}-i_{s 0}^{*}=\frac{\left(u_{s q^{*} 0}-R_{s} i_{s 0}-n_{p} \lambda_{r} \omega_{r} \sin \theta_{L}\right)}{L_{q *}}-i_{s 0}^{*} .
$$

Control variable $u_{s q 0 *}$ can be designed as follows:

$$
u_{s q * 0}=-L_{q *} k_{i} e_{i}+L_{q *} i_{s 0}^{*}+R_{s} i_{s 0}+n_{p} \lambda_{r} \omega_{r} \sin \theta_{L}
$$

where $k_{i}$ is a pending positive number. By substituting equation (29) into equation (28), equation (28) can be rewritten as

$$
\dot{e}_{i}=-k_{i} e_{i}
$$

Due to

$$
\theta_{L k}^{*}=k \theta_{L}^{*}
$$

and $e_{\theta k}=\theta_{L k}-\theta_{L k}^{*}$, the derivative of $e_{\theta}$ could be expressed as

$$
\dot{e}_{\theta k}=\dot{\theta}_{L k}-\dot{\theta}_{L k}^{*}=\left(\frac{\left(-u_{s d^{*} k}-k n_{p} \lambda_{r k} \omega_{r} \cos \theta_{L k}-k n_{p} \omega_{i} L_{q *} i_{s k}\right)}{L_{q *} i_{s k}}-\dot{\theta}_{L k}^{*}\right) .
$$

Control variable $u_{s d k *}$ can be chosen as

$$
\begin{aligned}
u_{s d k *}= & -L_{q *} i_{s k} \dot{\theta}_{L k}^{*}-k n_{p} \lambda_{r k} \omega_{r} \cos \theta_{L k}-k n_{p} \omega_{i} L_{q *} i_{s k} \\
& +L_{q *} i_{s k} k_{\theta k} e_{\theta k}
\end{aligned}
$$

where $k_{\theta k}$ is a pending positive number. By substituting equation (33) into equation (32), equation (32) will be rewritten as

$$
\dot{e}_{\theta k}=-k_{\theta k} e_{\theta k}
$$

Because $i_{s k}^{*}$ equals to $I_{s k}^{\mathrm{opt}}$ and $e_{i k}=i_{s k}-i_{s k}^{*}$, the derivative of $e_{i k}$ can be calculated as

$$
\dot{e}_{i k}=\dot{i}_{s k}-\dot{i}_{s k}^{*}=\frac{\left(u_{s q^{*} k}-R_{s} i_{s k}-k n_{p} \lambda_{r k} \omega_{r} \sin \theta_{k L}\right)}{L_{q *}}-\dot{i}_{s k}^{*} .
$$

Control variable $u_{s d k *}$ can be chosen as

$$
u_{s q k *}=R_{s} i_{s k}+k n_{p} \lambda_{r k} \omega_{r} \sin \theta_{k L}+L_{q *} i_{s k}^{*}-L_{q *} k_{i k} e_{i k} \text {, }
$$

where $k_{i k}$ is a pending positive number. By substituting equation (36) into equation (35), equation (35) will be rewritten as

$$
\dot{e}_{i k}=-k_{i k} e_{i k}
$$

Based on the above derivation, a closed-loop $I / f$ controller used for suppressing torque ripple and meanwhile guaranteeing minimum electrical loss is proposed. The final voltage control equations of the proposed controller are

$$
\begin{aligned}
u_{s q *}= & -L_{q *} k_{i} e_{i}+L_{q *} i_{s 0}^{*}+R_{s} i_{s 0}+n_{p} \lambda_{r} \omega_{r} \sin \theta_{L} \\
& +\sum_{k}\left(R_{s} i_{s k}+k n_{p} \lambda_{r k} \omega_{r} \sin \theta_{L k}+L_{q *} i_{s k}^{*}-L_{q *} k_{i k} e_{i k}\right),
\end{aligned}
$$

$$
\begin{aligned}
u_{s d *}= & -L_{\mathrm{q} *} i_{s 0} \dot{\theta}_{L}^{*}-n_{p} \lambda_{r} \omega_{r} \cos \theta_{L}-n_{p} \omega_{r} L_{\mathrm{q} *} i_{s 0} \\
& +\sum_{k}\left(-L_{\mathrm{q} *} i_{s k} \dot{\theta}_{L k}^{*}-k n_{p} \lambda_{r k} \omega_{r} \cos \theta_{L k}-k n_{p} \omega_{r} L_{\mathrm{q} *} i_{s k}\right. \\
& \left.+L_{\mathrm{q} *} i_{s k} k_{\theta k} e_{\theta k}\right) .
\end{aligned}
$$

The schematic of the control scenario is plotted in Figure 3, where speed identification and control parameters prediction will be investigated in the subsequent sections.

\section{Speed Identification of PMSM Based on the Least-Squares Method}

The control performance of the proposed method relies on precise speed information. A sensor-less speed identification algorithm is presented in this section. In general, the speed identification algorithm of PMSM could be divided into two types of low speed and high speed. For medium-low speed, the injection of various high-frequency signals [22, 23] is widely used to acquire speed information that will inevitably give rise to unnecessary torque ripple. For medium-high speed, applications of stator flux linkage versus position feature $[24,25]$ and various observers such as sliding mode $[26,27]$ and extended Kalman filter (EKF) $[28,29]$ to detect rotor position are normally used. To obtain the stator flux linkage, it is necessary to integrate back electromotive force. But the integrator exhibits zero drift and phase shift during operation, which will limit the accuracy of estimation. The controller of sliding mode is simple and easy to implement, but it may cause the system to chatter. EFK has a strong antiinterference ability. However, it relies heavily on the 


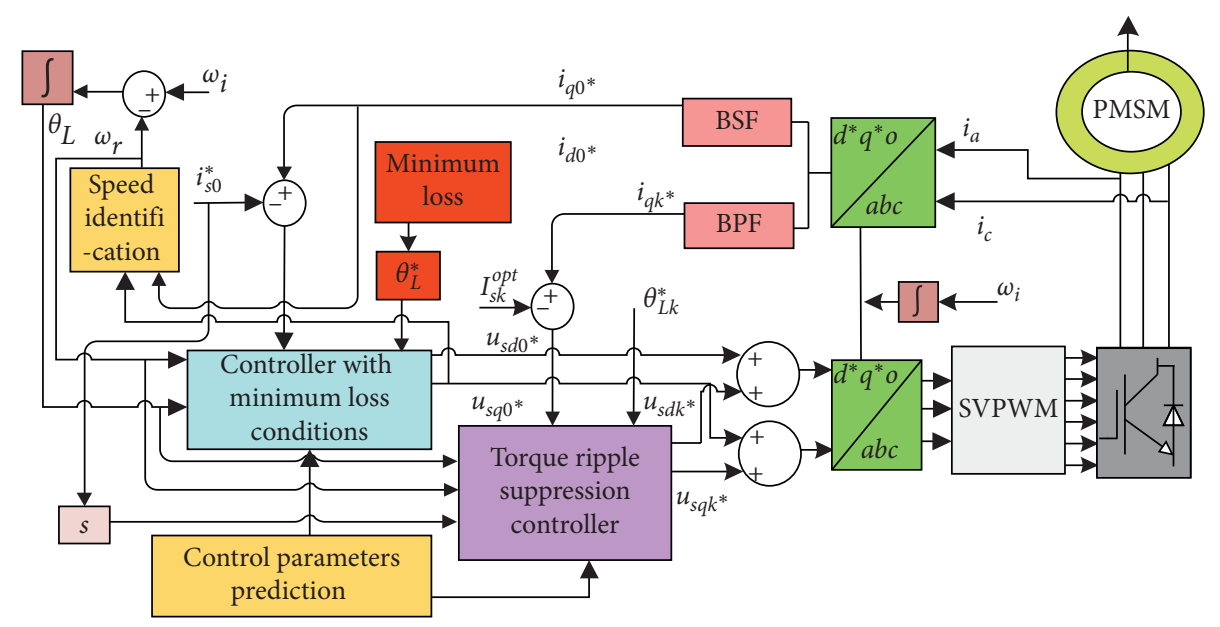

(a)

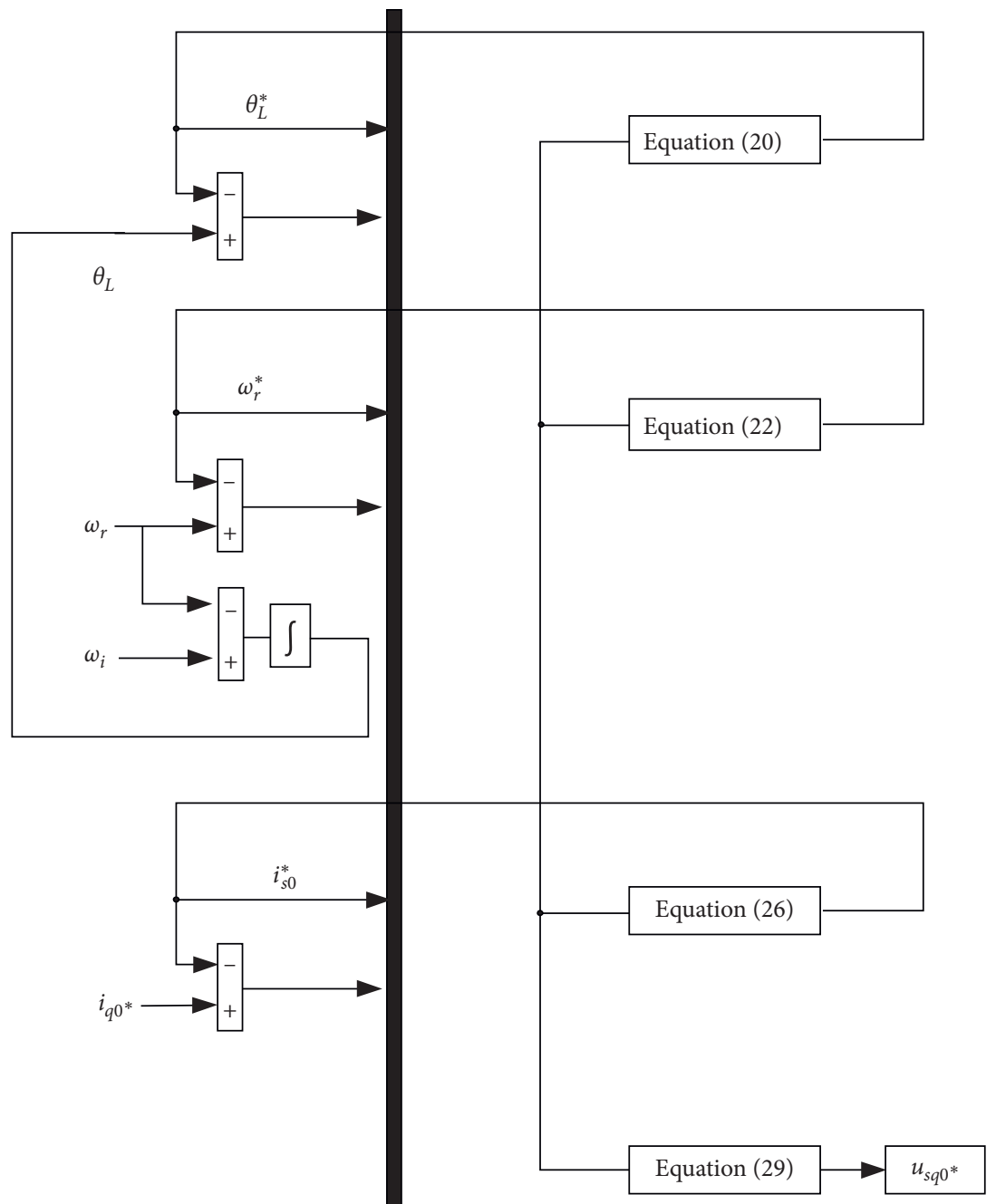

(b)

Figure 3: Continued. 


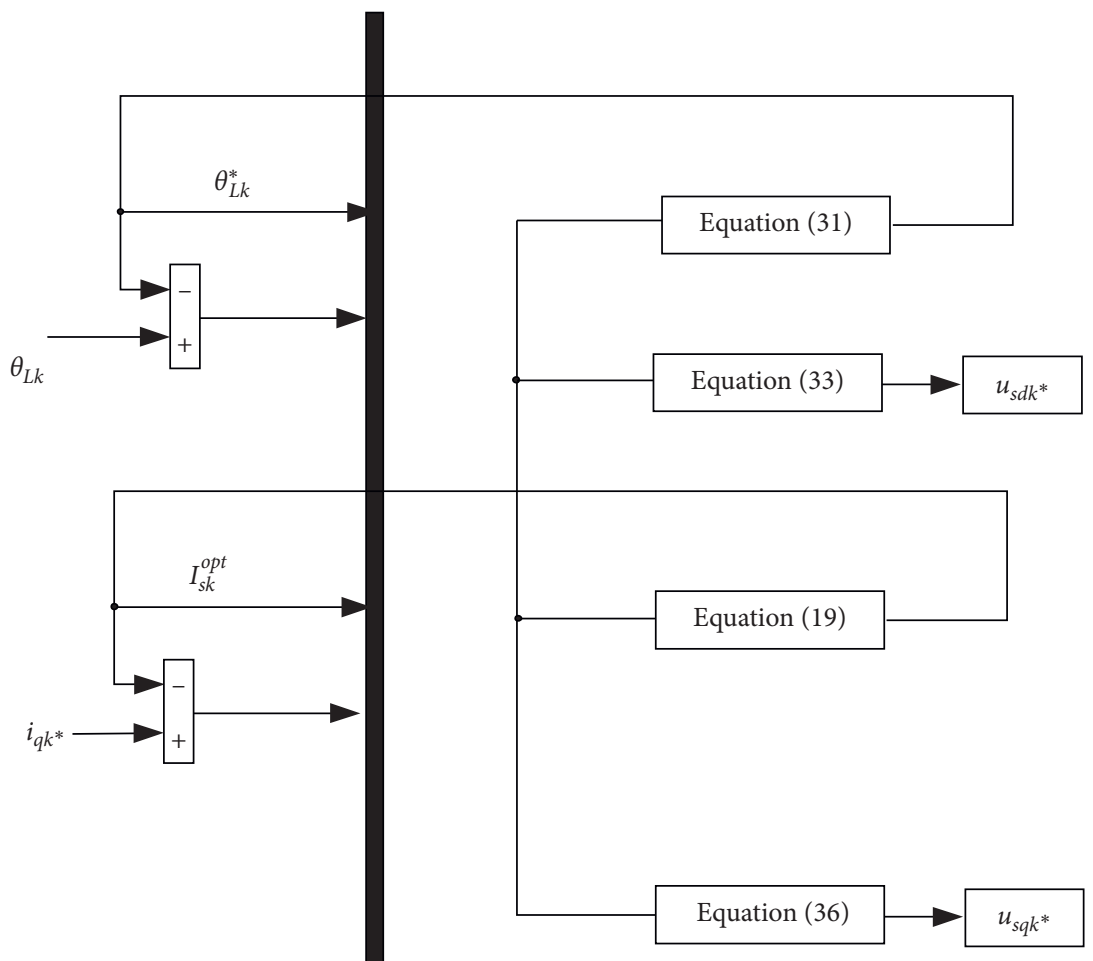

(c)

FIGURE 3: Structural diagram of the proposed controller. BSF: band-stop filter; BPF: band-pass filter. (a) Structural diagram of the proposed controller. (b) Mathematical model of the controller with minimum loss conditions. (c) Mathematical model of the torque ripple suppression controller.

parameters of the motor and the algorithm is relatively complex which requires a larger computation.

The least-squares method with a forgetting factor (LSFF) has been verified that it has an excellent performance to track a changing signal. The principle of LSFF is described as follows [30]:

$$
\left\{\begin{array}{l}
\widehat{B}(n)=\widehat{B}(n-1)+\mathbf{L}(n)\left[\mathbf{y}(n)-\boldsymbol{\varphi}^{T}(n) \widehat{B}(n-1)\right] \\
\mathbf{L}(n)=\left(\frac{\mathbf{P}(n-1) \boldsymbol{\varphi}(n)}{\left(\xi+\boldsymbol{\varphi}^{T}(n) \mathbf{P}(n-1) \varphi(n)\right)}\right) \\
\mathbf{P}(n)=\left(\frac{\left[\mathbf{P}(n-1)-\mathbf{L}(k) \boldsymbol{\varphi}^{T}(n) \mathbf{P}(n-1)\right]}{\xi}\right)
\end{array}\right.
$$

where $\boldsymbol{B}$ indicates the identified parameters that could be a multidimensional vector; $\boldsymbol{L}, \boldsymbol{P}$, and $\boldsymbol{\varphi}$ are the vectors of gain, covariance, and information; $y$ produces the outputs; $n$ represents the sampling point; and $\xi$ is the forgetting factor, $0<\xi \leq 1$.
In allusion to the insufficiency in present algorithms of speed identification, LSFF in the study is used to estimate the rotor position of PMSM and the identified structure is built as follows:

$$
\left\{\begin{array}{l}
\left(-n_{p} \lambda_{r} \cos \left(\theta_{L}(n)\right)\right) \omega_{r}(n)=u_{s d *}(n)+n_{p} \omega_{r}(n) L_{q *} i_{s}(n) \\
+L_{q *} i_{s}(n)\left(\frac{\left(\theta_{L}(n)-\theta_{L}(n-1)\right)}{T_{s}}\right) \\
\left(n_{p} \lambda_{r} \sin \left(\theta_{L}(n)\right)\right) \omega_{r}(n)=u_{s q *}(n)-R_{s} i_{s}(n) \\
-L_{q *}\left(\frac{\left(i_{s}(n)-i_{s}(n-1)\right)}{T_{s}}\right)
\end{array}\right.
$$

where $T_{s}$ is the sampling time. Compared with equation (40), the variables required in speed identification from equation (41) are 


$$
\left\{\begin{array}{l}
y(n)=\left[\begin{array}{c}
u_{s q *}(n)-R_{s} i_{s}(n)-L_{q *} \frac{\left(i_{s}(n)-i_{s}(n-1)\right)}{T_{s}} \\
u_{s d *}(n)+n_{p} \omega_{r}(n) L_{q *} i_{s}(n)+L_{q *} i_{s}(n)\left(\frac{\left(\theta_{L}(n)-\theta_{L}(n-1)\right)}{T_{s}}\right)
\end{array}\right], \\
\varphi(n)=\left[\begin{array}{l}
n_{p} \lambda_{r} \\
-n_{p} \lambda_{r}
\end{array}\right], \\
\widehat{B}(n)=\left[\begin{array}{l}
\omega_{r}(n) \sin \left(\theta_{L}(n)\right) \\
\omega_{r}(n) \cos \left(\theta_{L}(n)\right)
\end{array}\right] .
\end{array}\right.
$$

By substituting equation (42) into equation (40), the identification law of rotor speed for PMSM is completed.

\section{Online Prediction of Control Parameters}

Backstepping control has obvious potential advantages in controlling uncertain nonlinear systems [31]. Merely, the control gains in backstepping control lack the ability to adjust to the operating conditions adaptively. Model predictive control (MPC) provides an effective method to deal with uncertain problems by optimizing a given objective function online [32-34]. MPC is introduced in this section to propose a nonlinear predictive algorithm that online optimizes control parameters in backstepping control and improves the robustness of the controller. In order to satisfy the needs of online computation, the model of the system is discretized through the differential method and shown in equation (43).

$$
\left\{\begin{array}{l}
T_{e}(n)=\frac{3}{2} n_{p} \lambda_{r} i_{w q}(n), R_{c} i_{c d}(n)=-n_{p} \omega_{r} L_{q} i_{w q}(n), R_{c} i_{c q}(n)=n_{p} \omega_{r}(n)\left(\lambda_{r}+L_{d} i_{w d}(n)\right), \\
i_{d r e f}(n)=-\frac{\left(n_{p} \omega_{r}(n) L_{q} i_{w q}(n)\right)}{R_{c}}-\frac{\left(n_{p}^{2} \omega_{r}^{2}(n) \lambda_{r} L_{d} R_{c}\right)}{\left(R_{s} R_{c}^{2}+n_{p}^{2} \omega_{r}^{2}(n) L_{d}^{2}\left(R_{s}+R_{c}\right)\right)} \\
i_{s 0}(n+1)=i_{s 0}(n)+\left(\frac{T_{s}}{L_{q *}}\right)\left(u_{s q *}(n)-R_{s} i_{s 0}(n)-n_{p} \lambda_{r} \omega_{r}(n) \sin \left(\theta_{L}(n)\right)\right), \\
\omega_{r}(n+1)=\omega_{r}(k)+T_{s} \frac{\left(T_{e}(n)-T_{L}(n)-B \omega_{r}(n)\right)}{J}, \\
i_{s k}(n+1)=i_{s k}(n)+\left(\frac{T_{s}}{L_{q *}}\right)\left(u_{s q * k}(n)-R_{s} i_{s k}(n)-k n_{p} \lambda_{r k} \omega_{r}(n) \sin \left(\theta_{L k}(n)\right)\right), \\
\theta_{L}(n+1)=\theta_{L}(n)+T_{s} n_{p}\left(\omega_{i}(n)-\omega_{r}(n)\right), \\
\theta_{L k}(n+1)=\theta_{L k}(n)+T_{s} \frac{\left(-u_{s d^{*} k}(n)-k n_{p} \lambda_{r k} \omega_{r}(n) \cos \theta_{L k}(n)-k n_{p} \omega_{i}(n) L_{\mathrm{q} *} i_{s k}(n)\right)}{L_{q *} i_{s k}(n)}
\end{array}\right.
$$


Then, virtual control variables $\theta_{L}^{*}, \omega_{r}{ }^{*}$, and $i_{s 0}^{*}$ are discretized as equation (44), and the voltage control equations are

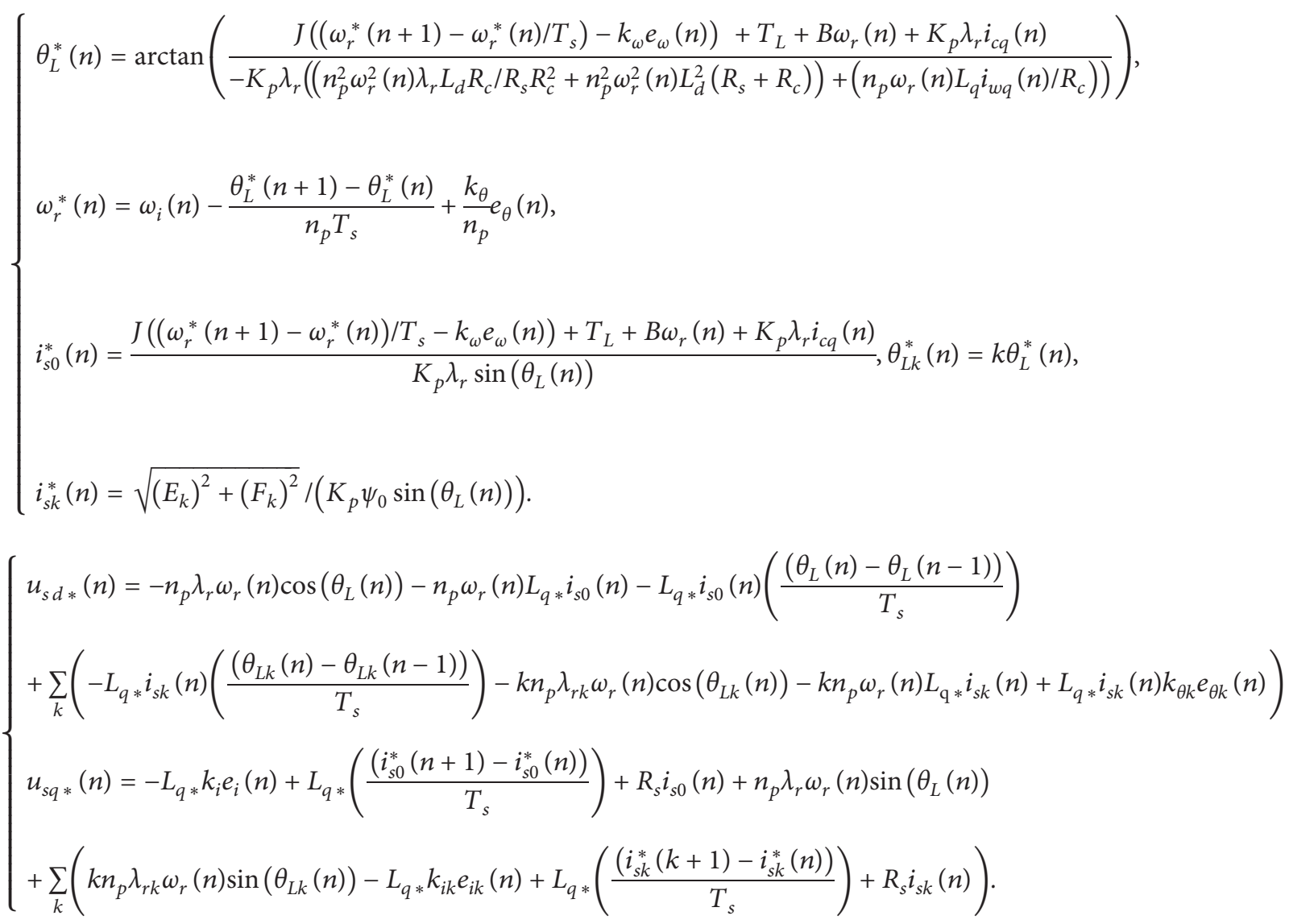

The objective function $F$ is selected as follows:

$$
F(n)=\sum_{i=1}^{M-1}\left(\mathbf{e}^{T}(n+i) \mathbf{E} \mathbf{e}(n+i)\right),
$$

where $\mathbf{e}=\left[e_{\theta}, e_{\omega}, e_{i}, e_{\theta k}, e_{i k}\right]^{T}, M$ is the predictive time domain, and $\mathbf{E}$ is a positive definite matrix. The control parameters $\mathbf{K}=\left[k_{\theta}, k_{\omega}, k_{i}, k_{\theta k}, k_{i k}\right]$ that make the objective function to be optimal can be obtained by solving constrained linear programming online:

\section{Simulation and Experimental Analysis}

6.1. Simulation Certification. The simulations performed in MATLAB are designed to testify the control method proposed in this section. The study has revealed that only a finite number of harmonics occupy the dominant position in PMSM. Their frequencies are the numbers of six times in $d q o$ coordinate frame, such as the 6th, 12th, and 18th [35]. The investigation in the study demonstrates that the sixth harmonic component occupies a dominant place in total harmonic components, which is selected to be suppressed. The parameters of PMSM are described in Table 1.
The result of the first case is given in Figure 4 to validate the proposed least-squares speed estimation algorithm. Two sets of reference steady-state speed are determined as $20 \mathrm{r} /$ min and $150 \mathrm{r} / \mathrm{min}$ to represent low, medium, and high speeds, respectively. It is clear that the estimation algorithm can track a certain range of reference speeds rapidly and accurately, and the effectiveness of the algorithm is proved.

The second case compares closed-loop $I / f$ control with existing $I / f$ control without considering torque ripple and electrical loss. The load torque $T_{L}$ is $15 \mathrm{~N} \cdot \mathrm{m}$ and PMSM starts up from standstill to $60 \mathrm{r} / \mathrm{min}$. Comparative control performances are given in Figure 5. Compared to the conventionally open-loop $I / f$ control with a larger amplitude of stator current and speed ripple, significant superiority of closed-loop $I / f$ control is less energy consumption and more stable speed.

The controller of torque ripple suppression without electrical loss is tested in the third case. The load torque $T_{L}$ is $15 \mathrm{~N} \cdot \mathrm{m}$, and PMSM starts up from standstill to $60 \mathrm{r} / \mathrm{min}$. Backstepping controls with and without torque ripple suppression are taken into effect at $15 \mathrm{~s}$, respectively, and the results are plotted in Figures 6(a)-6(d). With the aid of the 
TABle 1: Parameters of PMSM.

\begin{tabular}{lc}
\hline Parameters & Value \\
\hline Stator inductance & $0.033 \mathrm{H}$ \\
Stator resistance & $2.875 \Omega$ \\
Iron loss resistance & $300 \Omega$ \\
Number of pole pairs & 50 \\
Permanent magnet flux linkage & $0.3 \mathrm{~Wb}$ \\
Inertia & $0.51 \mathrm{~kg} \mathrm{~m}{ }^{2}$ \\
Viscous coefficient & $0.02 \mathrm{~N} / \mathrm{m} / \mathrm{s}$ \\
\hline
\end{tabular}

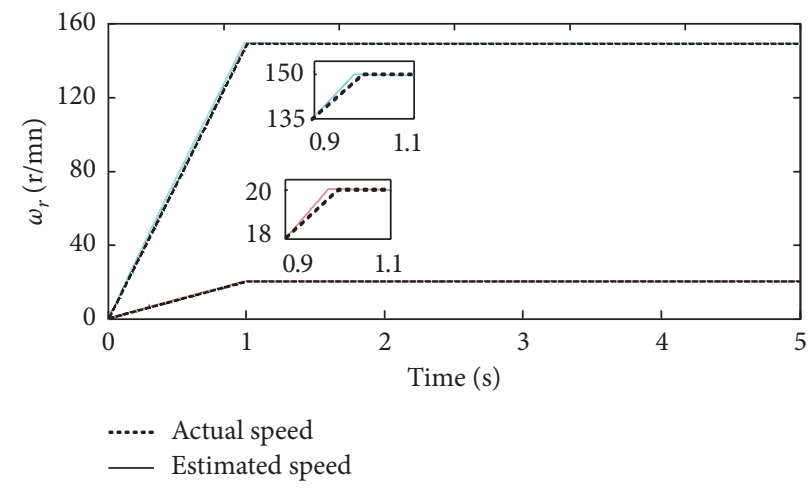

FIGURE 4: Speed curves with the least-square-based speed estimation algorithm.

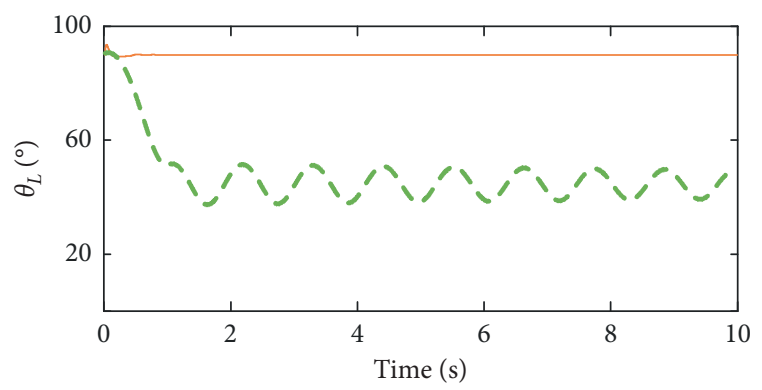

— Closed-loop $I / f$

.... Conventional $I / f$

(a)

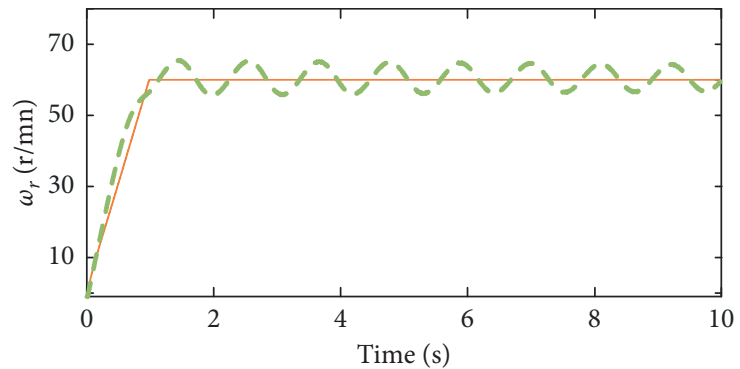

_ Closed-loop I/f

.... Conventional I/f

(b)

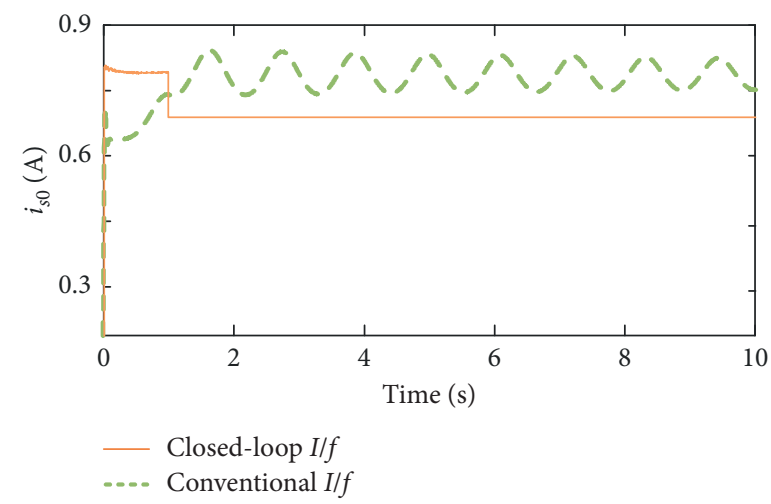

(c)

FIGURE 5: Comparative results between closed-loop I/f control and conventional I/f control. (a) $\theta_{L}$, (b) $\omega_{r}$, and (c) $i_{s 0}$. 


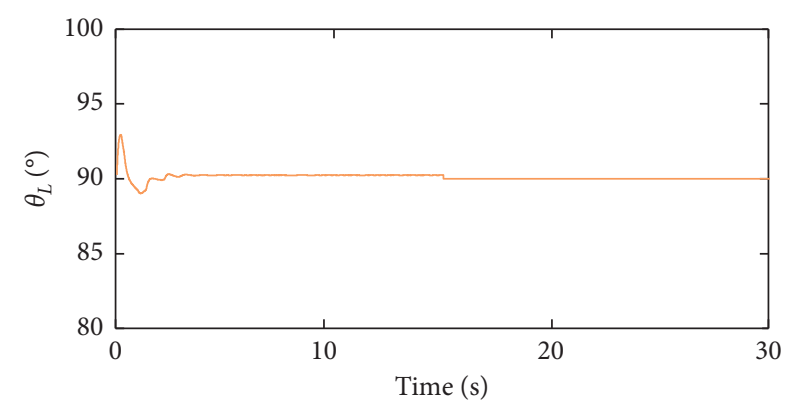

(a)

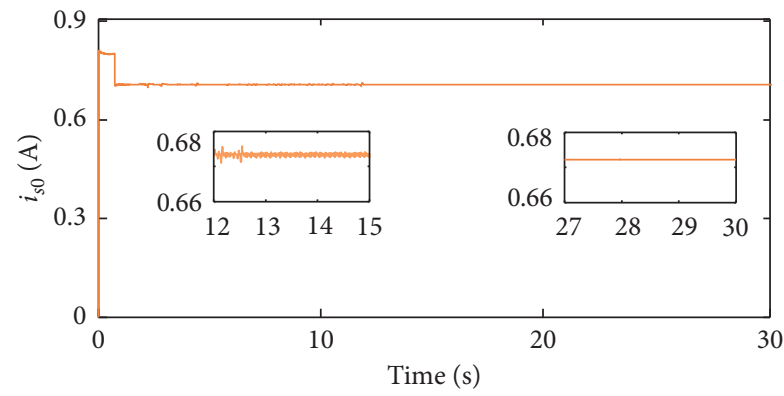

(c)

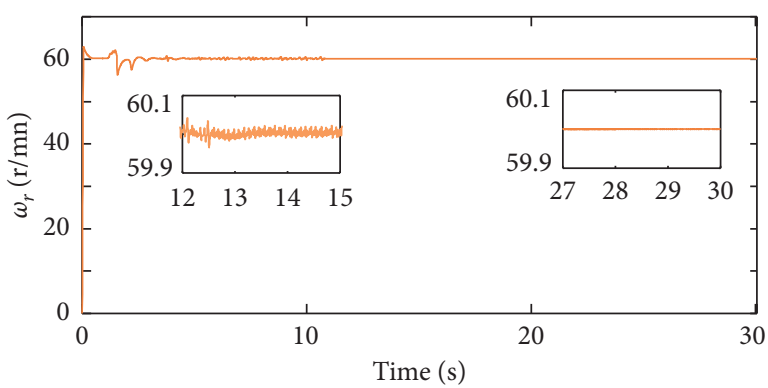

(b)

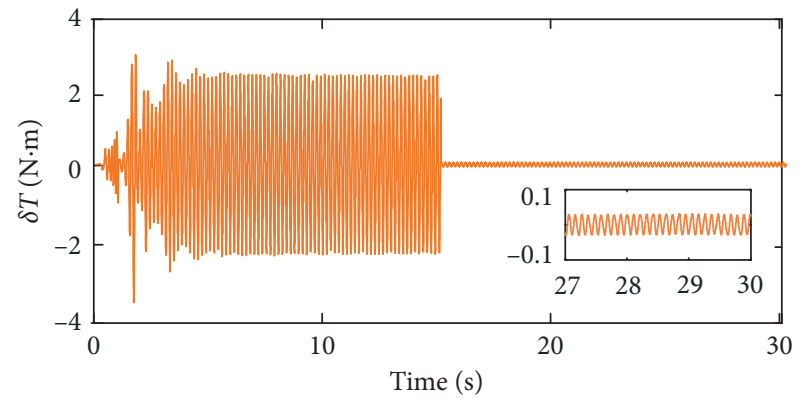

(d)

FIGURE 6: Comparative results of the proposed controller with and without torque ripple suppression. (a) $\theta_{L}$, (b) $\omega_{r}$, (c) $i_{s 0}$, and (d) $\delta T$.

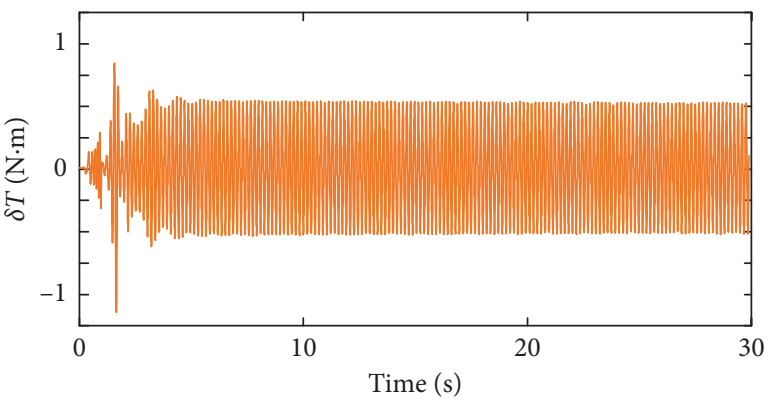

(a)

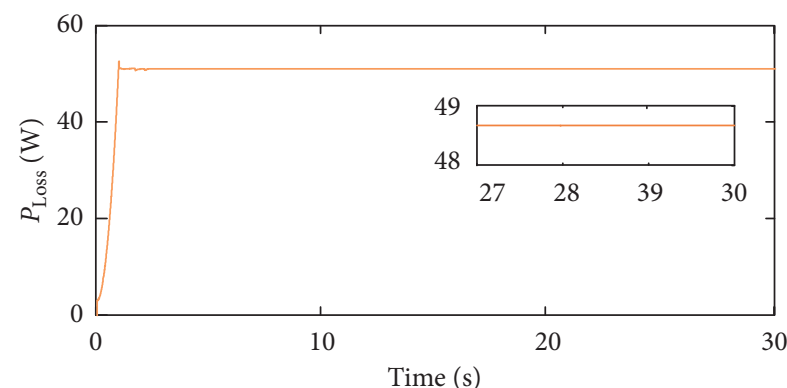

(b)

FIgURE 7: Results of the torque ripple suppression controller while considering electrical loss. (a) $\delta T$ and (b) $P_{\text {Loss. }}$

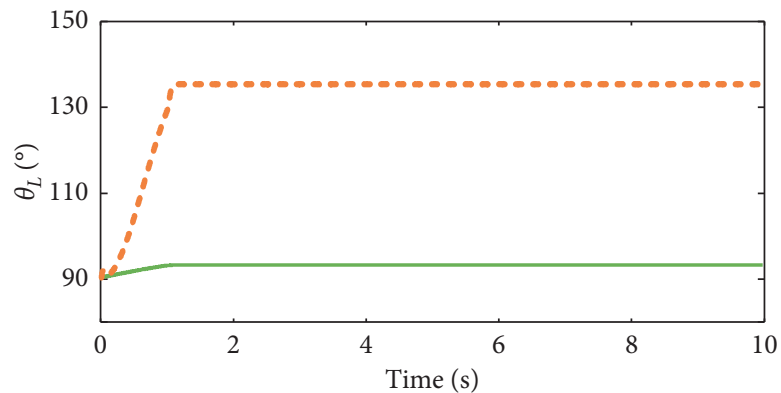

-.. With optimal electrical loss Without optimal electrical loss

(a)

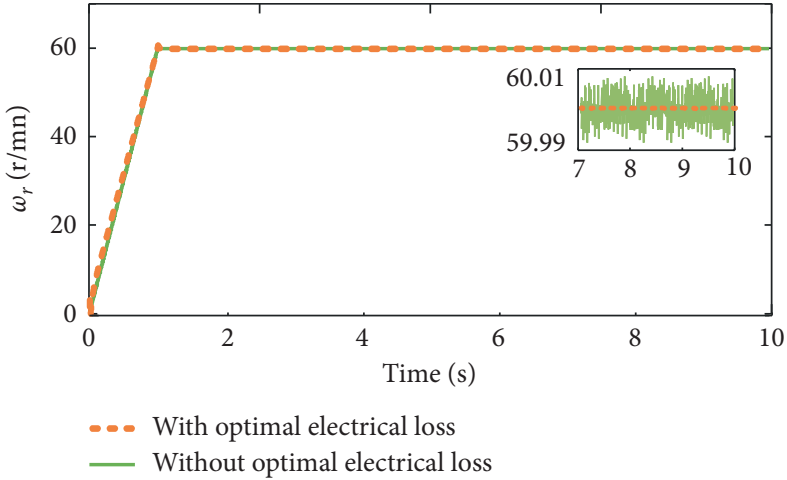

(b)

Figure 8: Continued. 


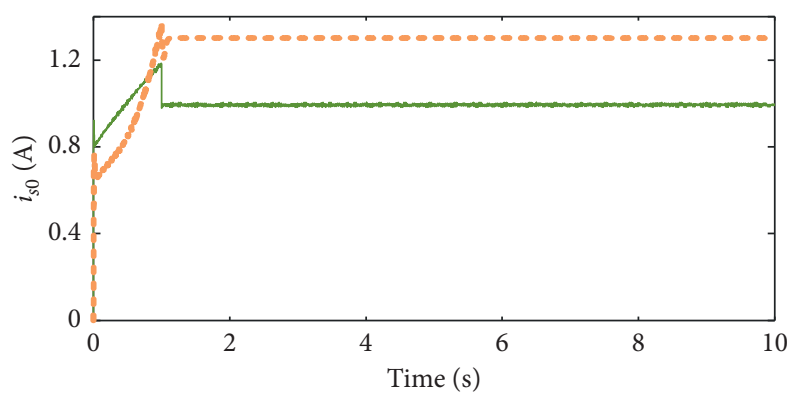

-.. With optimal electrical loss

_ Without optimal electrical loss

(c)

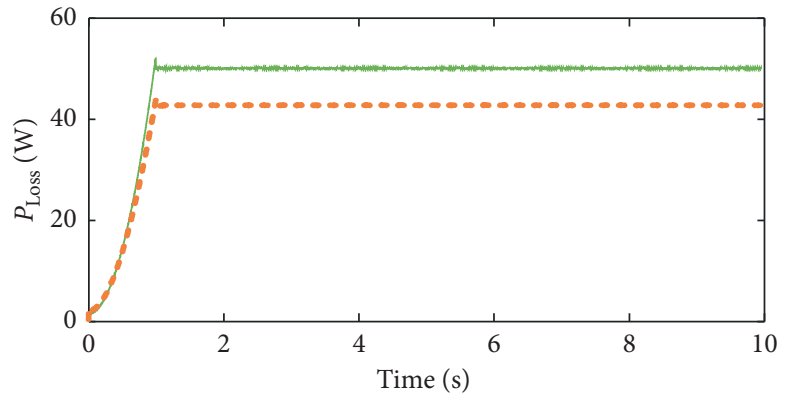

-. With optimal electrical loss

_ Without optimal electrical loss

(d)

FIgURE 8: Comparative results of the proposed controller with and without optimal electrical loss. (a) $\theta_{L}$, (b) $\omega_{r}$, (c) $i_{s 0}$, and (d) $P_{\text {Loss. }}$.

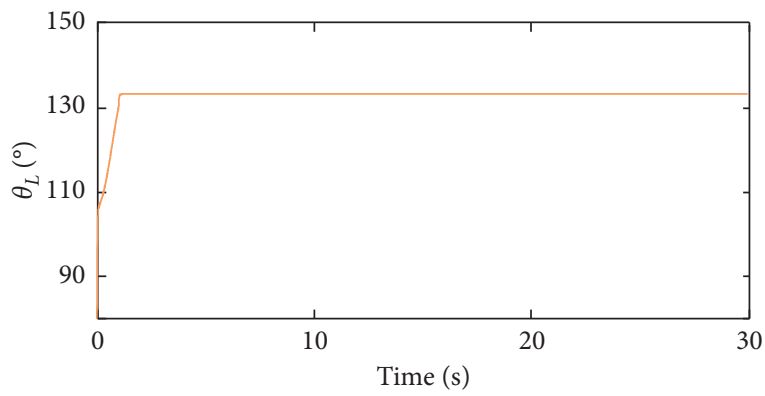

(a)

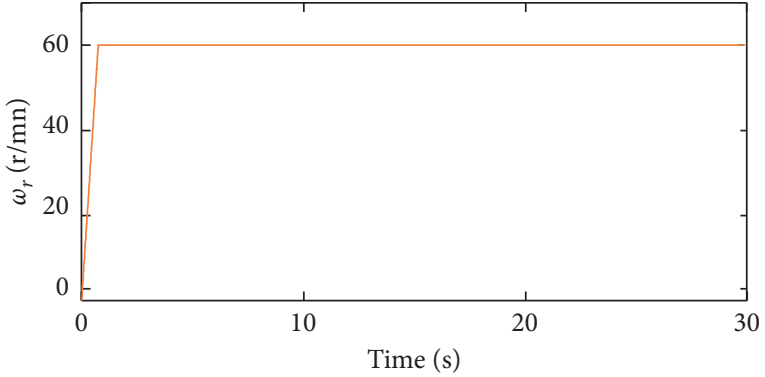

(b)

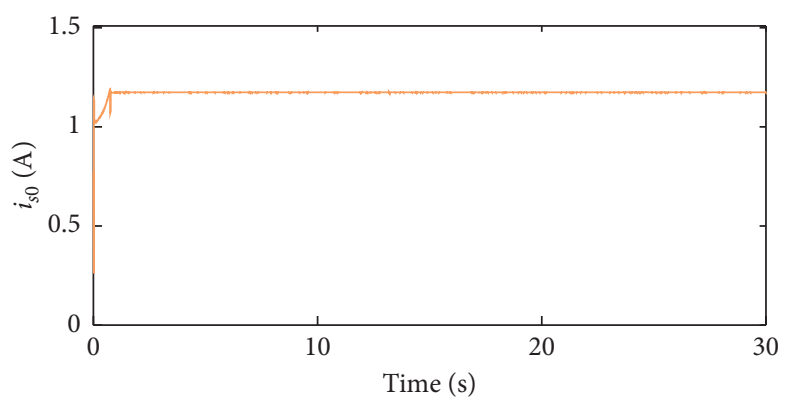

(c)

Figure 9: Testing results of the proposed control scheme considering torque ripple and electrical loss. (a) $\theta_{L}$, (b) $\omega_{r}$, and (c) $i_{\mathrm{s} 0}$.

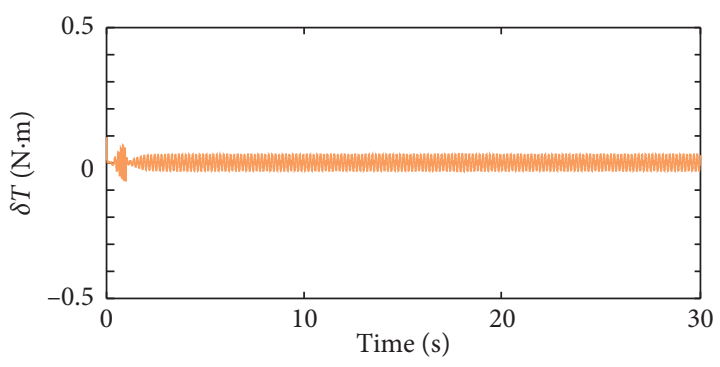

(a)

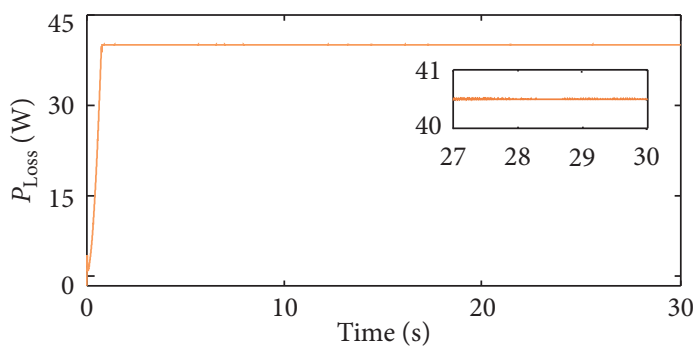

(b)

Figure 10: Testing results of the proposed control scheme considering torque ripple and electrical loss. (a) $\delta$ T and (b) $P_{\text {Loss. }}$ 


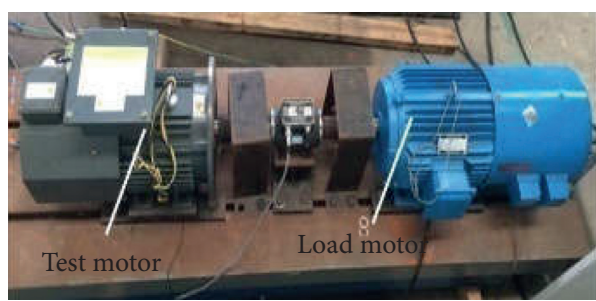

(a)

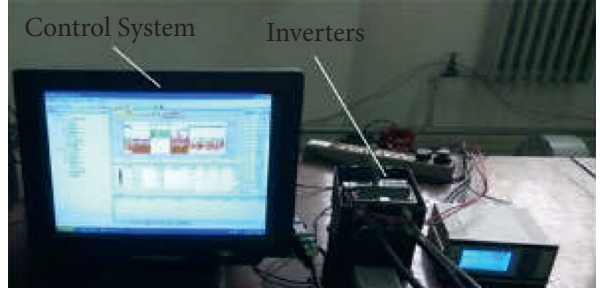

(b)

FIgURE 11: Hardware platform. (a) Test motor and load motor. (b) Control system and inverters.

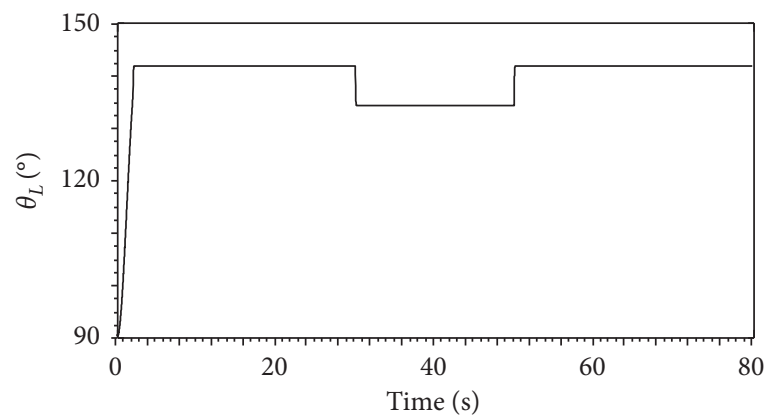

(a)

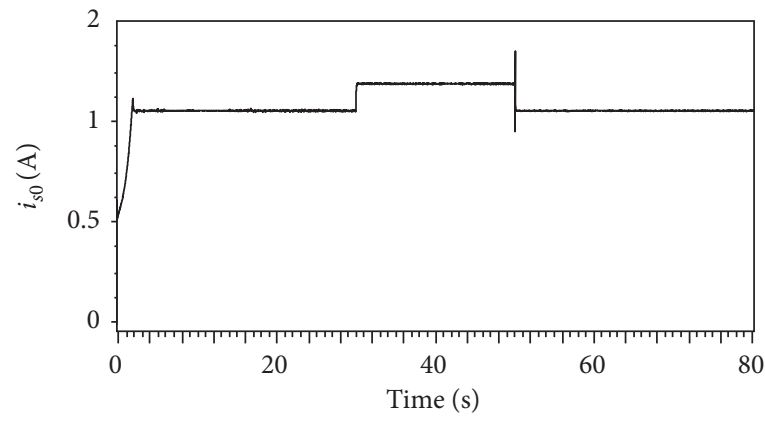

(c)

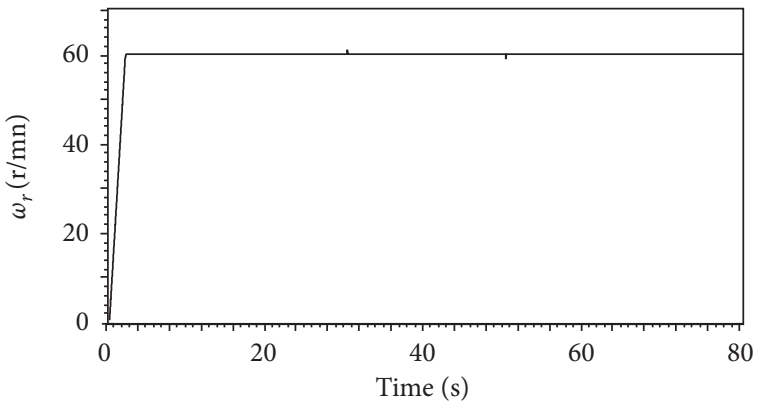

(b)

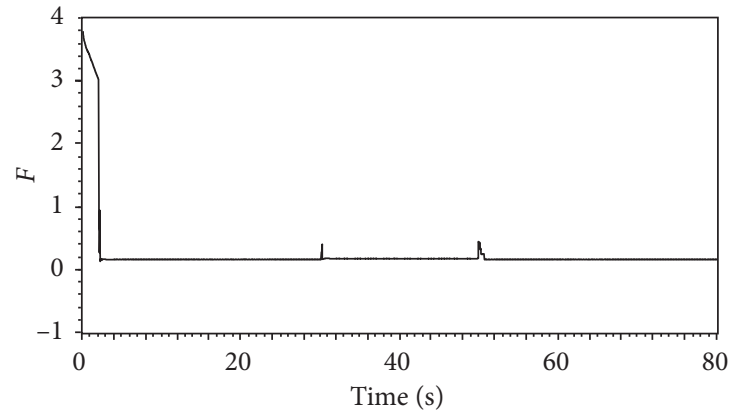

(d)

FIGURE 12: Results of the proposed closed-loop I/f control method with varying load. (a) $\theta_{L}$, (b) $\omega_{r}$, (c) $i_{s 0}$, and (d) $F$.

torque ripple suppression algorithm, operating parameters are more stable, and the peak-to-peak value of torque ripple reduces from more than $5 \mathrm{~N} \cdot \mathrm{m}$ to less than $0.1 \mathrm{~N} \cdot \mathrm{m}$. In practice, the electrical loss that is unavoidable, while taking electrical loss into account, the torque ripple $\delta T$, and total electrical loss $P_{\text {Loss }}$ in the simulation are plotted in Figures 7(a)-7(b). Compared with Figure 6(d), the electrical loss will adversely affect the control performance of torque ripple suppression and $P_{\text {Loss }}$ turns out to be quite large which is hard to be ignored.

The fourth case is designed to testify the effectiveness of minimum electrical loss control. The load torque $T_{L}$ is $15 \mathrm{~N} \cdot \mathrm{m}$, and PMSM starts up from standstill to $60 \mathrm{r} / \mathrm{min}$. The results of backstepping control with and without considering the constraint condition of optimal electrical loss are presented in Figures 8(a)-8(d). Apparently, consideration of optimal loss constraint condition enables to decrease energy consumption and stabilizes operation variables of PMSM effectively.

The fifth case will investigate the closed-loop $I / f$ control proposed in the context that integrates torque ripple suppression with optimal electrical loss simultaneously. The load torque $T_{L}$ is $15 \mathrm{~N} \cdot \mathrm{m}$ and PMSM starts up from standstill to $60 \mathrm{r} / \mathrm{min}$. Figures 9(a)-9(c) and Figures 10(a)10(b) display the operating parameters, torque ripple $\delta T$, and total electrical loss $P_{\text {Loss. }}$ In this way, the peak-to-peak value of torque ripple is suppressed to less than $0.1 \mathrm{~N} \cdot \mathrm{m}$. And in comparison with Figure $7(\mathrm{~b}), P_{\text {Loss }}$ is reduced from $48.7 \mathrm{~W}$ to $40.5 \mathrm{~W}$. It can be seen that with the proposed closed-loop $I / f$ controller, all variables are regulated to be more stable torque ripple is suppressed effectively, and electrical loss is reduced to a certain extent. The stability and operating efficiency of PMSM are significantly enhanced. 


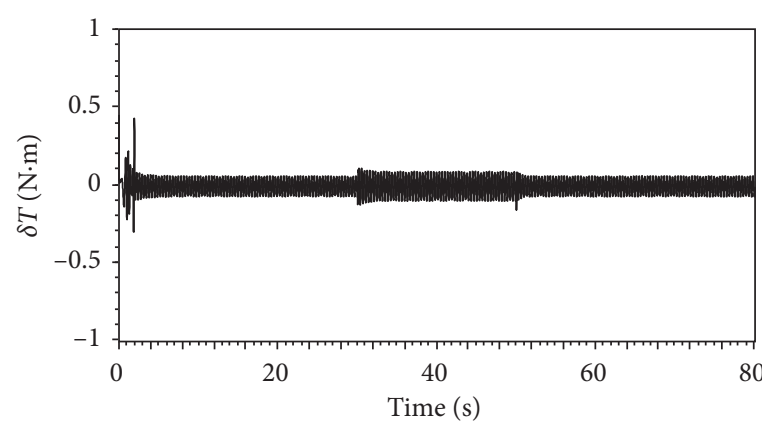

(a)

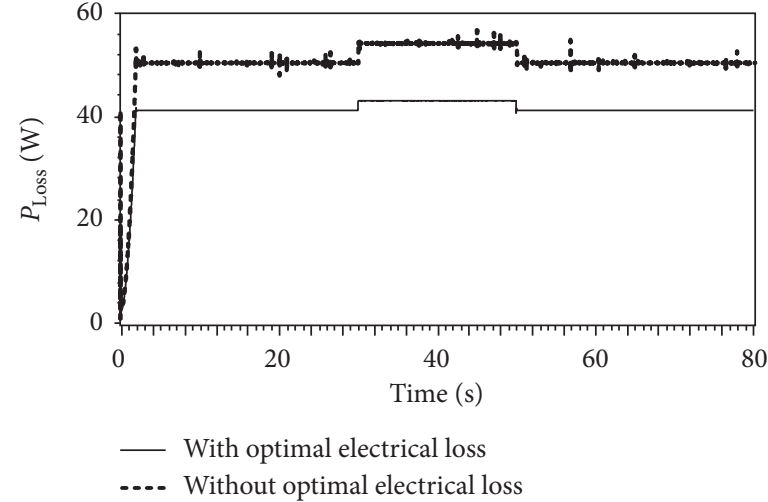

(b)

Figure 13: Results of the proposed closed-loop I/ $f$ control method with varying load. (a) $\delta T$ and (b) $P_{\text {Loss. }}$.

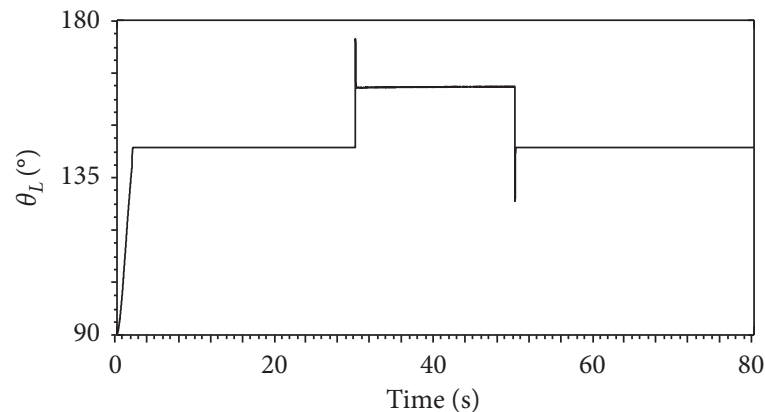

(a)

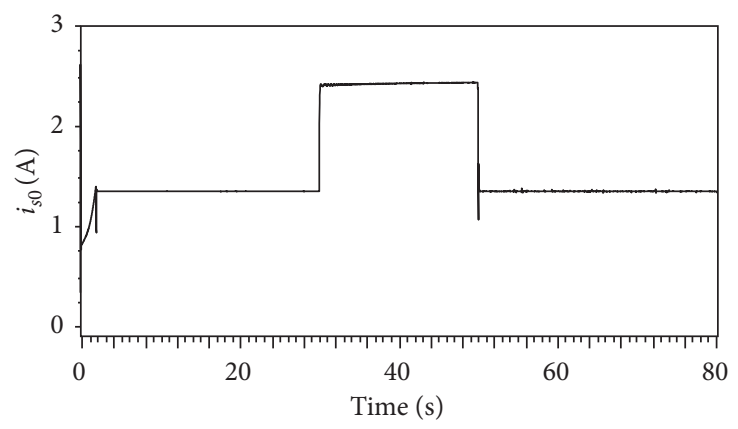

(c)

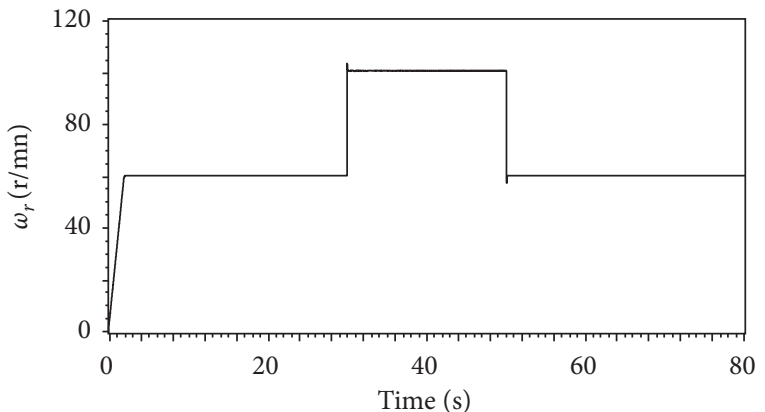

(b)

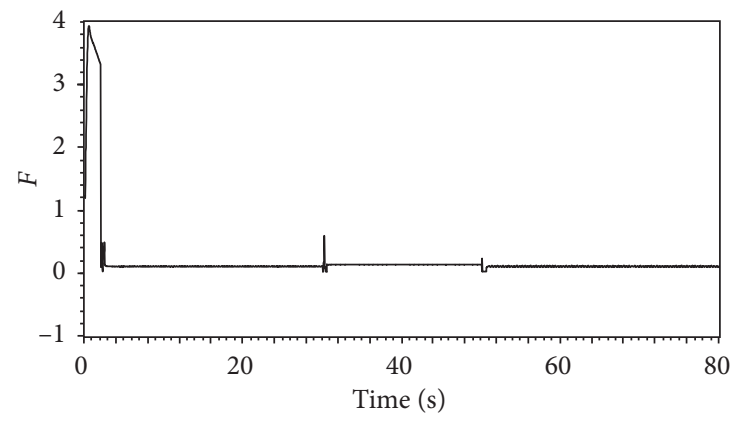

(d)

FIgURE 14: Results of the proposed closed-loop $I / f$ control method with varying speed. (a) $\theta_{L}$, (b) $\omega_{r}$, (c) $i_{s 0}$, and (d) $F$.

6.2. Hardware Setup and Implementation. In order to further verify the algorithm proposed in this paper, a hardware platform is established and exhibited in Figure 11. In this section, the dynamic performance of the proposed closedloop I/f control method is tested where the parameters of PMSM are consistent with the simulation.

The first experiment is to test the control performance of PMSM with the proposed control when load torque changes suddenly. PMSM starts up from standstill to $60 \mathrm{r} /$ min. The load torque $T_{L}$ is firstly set to be $10 \mathrm{~N} \cdot \mathrm{m}$ and increases to $15 \mathrm{~N} \cdot \mathrm{m}$ at $30 \mathrm{~s}$. Then, it decreases to be $10 \mathrm{~N} \cdot \mathrm{m}$ at $50 \mathrm{~s}$ and lasts to the end. Figures 12(a)-12(c) indicate the operating variables. Figure 13(a) gives the waveform of torque ripple $\delta T$. Figure 13(b) compares the results of total electrical loss $P_{\text {Loss }}$ with and without optimal electrical loss condition. When load torque changes suddenly, all the operating parameters will only suffer a slight oscillation and will restore to its reference very quickly. The proposed closed-loop I/f control can suppress torque ripple and improve operating efficiency. Meanwhile, it shows a good dynamic performance with a sudden variation of load torque. In this experiment, control parameters are firstly chosen by an online prediction algorithm as $\mathbf{K}=[94,80,283,121,177]$. While load torque changes suddenly, the prediction algorithm swiftly adjusts control parameters to $\mathbf{K}=[140,163,254,192,287]$. 


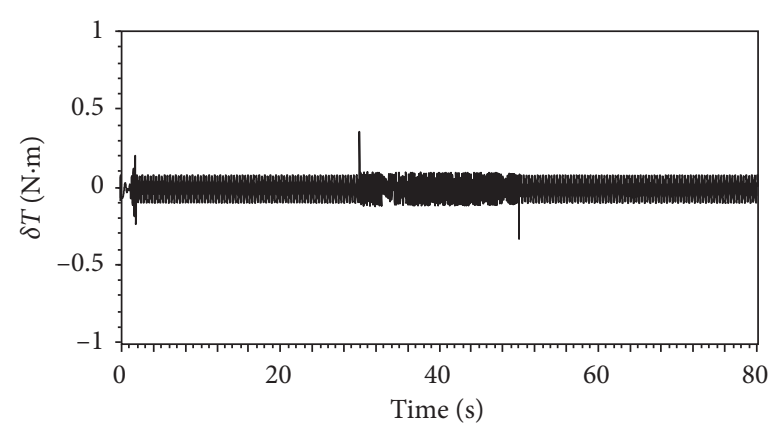

(a)

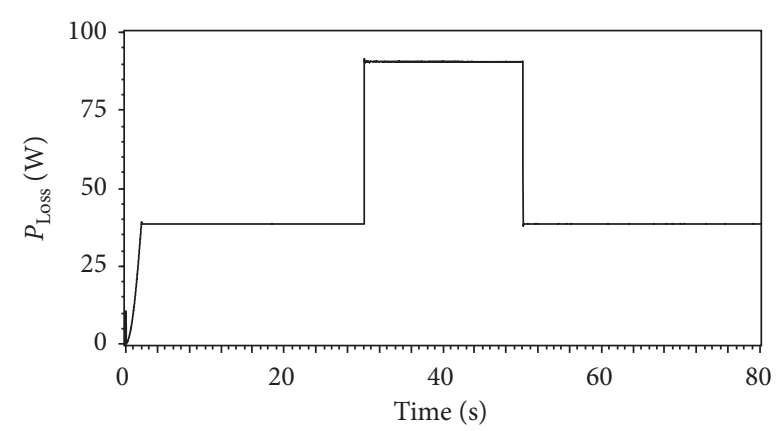

(b)

FIgURe 15: Results of the proposed closed-loop $I / f$ control method with varying speed. (a) $\delta T$ and (b) $P_{\text {Loss. }}$

The objective function $F$ is plotted in Figure 12(d), which indicates that control parameters can be quickly adjusted if load torque is abruptly changed.

The second experiment is to verify the control performance of PMSM with the proposed control when the speed reference changes suddenly. PMSM starts up from standstill to steady state and load torque $T_{L}$ is $15 \mathrm{~N} \cdot \mathrm{m}$. The reference speed is firstly set to be $60 \mathrm{r} / \mathrm{min}$ and increases to $100 \mathrm{r} / \mathrm{min}$ at $30 \mathrm{~s}$; then, it reduces to $60 \mathrm{r} / \mathrm{min}$ at $50 \mathrm{~s}$. The waveforms of various variables, torque ripple $\delta T$, and total electrical loss $P_{\text {Loss }}$ are, respectively, shown in Figures 14(a)-14(c) and 15(a)-15(b). When the speed reference changes suddenly, the variables will still only suffer a slight oscillation and will recover to its reference rapidly, which demonstrates a good dynamic performance with a sudden change of reference speed. In the experiment, control parameters are regulated from $\mathbf{K}=[94,80,283,121,177]$ to $\mathbf{K}=[207,188,314,268,192]$ when the speed reference has been changed suddenly at $15 \mathrm{~s}$. The objective function $F$ is presented in Figure 14(d) under the control of the proposed algorithm, which indicates that the proposed prediction algorithm is proved to be effective and robust.

\section{Conclusion}

This paper proposed a closed-loop $I / f$ control to combine torque ripple suppression with electrical loss. Meanwhile, this paper also makes some improvements on open-loop I/f control and nonadjustable control parameters of backstepping control. Feasibility and effectiveness of the proposed approach has been validated by both simulations and experiments. The conclusions are as follows:

(1) Through the proposed control scheme, the torque ripple of PMSM is suppressed effectively. Electrical loss of PMSM is significantly reduced, and operating efficiency is successfully improved.

(2) Every variable of PMSM operates stably with the proposed method; the ripple and oscillation of speed and current barely happen.

(3) The dynamic performance of the proposed method is remarkable. Even the reference signal suffers a sudden change; the whole system will remain stable.
Only a slight oscillation will occur at the moment of sudden change and all variables are able to recover to steady-state in a very short time.

(4) Online MPC algorithm for control parameters in backstepping control and speed estimation algorithm based on the least-squares method proposed in this paper significantly make up for the short-board of the existing algorithm and greatly improve the stability of the control scheme. However, the parameter optimization criterion used in the prediction algorithm is the sum of squared errors in each prediction period, which is not directly aimed at overshoot. Hence, we will aim at modifying the criterion and increasing the constraint on overshoot in the later research.

\section{Data Availability}

The data used to support the findings of this study are available from the corresponding author upon request.

\section{Conflicts of Interest}

The authors declare that they have no conflicts of interest.

\section{Acknowledgments}

This work was supported in part by the Natural Science Foundation of Hebei Province in China under Grant E2019502163, in part by the "Double-First Class" Scientific Research Project in School of Electrical and Electronic Engineering of North China Electric Power University under Grant 180718 and in part by the Headquarter of Science and Technology Project for Sate Grid Corporation of China under Grant KJGW 2018-014.

\section{References}

[1] V. Petrovic, R. Ortega, A. M. Stankovic, and G. Tadmor, "Design and implementation of an adaptive controller for torque ripple minimization in PM synchronous motors," IEEE Transactions on Power Electronics, vol. 15, no. 5, pp. 871-880, 2000.

[2] Y. Yu, L. Cong, X. Tian et al., "Simultaneous suppression of torque ripple and flexible load vibration for PMSM under 
stator current vector orientation," IET Electric Power Applications, vol. 13, no. 3, pp. 359-369, 2019.

[3] O. Wasynczuk, S. D. Sudhoff, K. A. Corzine et al., "A maximum torque per ampere control strategy for induction motor drives," IEEE Transactions on Energy Conversion, vol. 13, no. 2, pp. 163-169, 1998.

[4] R. J. Spiegel, M. W. Turner, and V. E. McCormick, "Fuzzylogic-based controllers for efficiency optimization of inverterfed induction motor drives," Fuzzy Sets and Systems, vol. 137, no. 3, pp. 387-401, 2003.

[5] R. Islam, I. Husain, A. Fardoun, and K. Mclaughlin, "Permanent-magnet synchronous motor magnet designs with skewing for torque ripple and cogging torque reduction," IEEE Transactions on Industry Applications, vol. 45, no. 1, pp. 152-160, 2009.

[6] D. Wang, X. Wang, M.-K. Kim, and S.-Y. Jung, "Integrated optimization of two design techniques for cogging torque reduction combined with analytical method by a simple gradient descent method," IEEE Transactions on Magnetics, vol. 48, no. 8, pp. 2265-2276, 2012.

[7] J. Wanjiku, M. A. Khan, P. S. Barendse, and P. Pillay, "Influence of slot openings and tooth profile on cogging torque in axial-flux pm machines," IEEE Transactions on Industrial Electronics, vol. 62, no. 12, pp. 7578-7589, 2015.

[8] W. Qian, S. K. Panda, and J. X. Xu, "Speed ripple minimization in PM synchronous motor using iterative learning control," IEEE Transactions on Energy Conversion, vol. 20, no. 1, pp. 53-61, 2005.

[9] Y. Yan, W. S. Li, W. T. Deng, G. Z. Zhang, and C. L. Xia, "Torque ripple minimization of PMSM using PI type iterative learning control," in Proceedings of the 40th Annual Conference of the IEEE Industrial Electronics Society, pp. 925-931, Dallas, TX, USA, October 2015.

[10] X. Xiao and C. Chen, "Reduction of torque ripple due to demagnetization in PMSM using current compensation," IEEE Transactions on Applied Superconductivity, vol. 20, no. 3, pp. 1068-1071, 2010.

[11] S. H. Hwang and J. M. Kim, "Dead time compensation method for voltage-fed PWM inverter," IEEE Transactions on Energy Conversion, vol. 25, no. 1, pp. 1-10, 2010.

[12] N. Urasaki, T. Senjyu, K. Uezato, and T. Funabashi, "An adaptive dead-time compensation strategy for voltage source inverter fed motor drives," IEEE Transactions on Power Electronics, vol. 20, no. 5, pp. 1150-1160, 2005.

[13] R. J. Kerkman, D. Leggate, D. W. Schlegel, and C. Winterhalter, "Effects of parasitics on the control of voltage source inverters," IEEE Transactions on Power Electronics, vol. 18, no. 1, pp. 140-150, 2003.

[14] M. T. Cao and Y. Hori, "Convergence improvement of efficiency-optimization control of induction motor drives," IEEE Transactions on Industry Applications, vol. 37, no. 6, pp. 1746-1753, 2001.

[15] E. Sergaki, P. Georgilakis, A. Kladas, and G. S. Stavrakakis, "Fuzzy logic based online electromagnetic loss minimization of permanent magnet synchronous motor drives," in Proceedings of the 18th International Conference on Electrical Machines, pp. 1-7, IEEE, Vilamoura, Portugal, September 2008.

[16] J. Lee, K. Nam, S. Choi, and S. Kwon, "Loss-minimizing control of PMSM with the use of polynomial approximations," IEEE Transactions on Power Electronics, vol. 24, no. 4, pp. 1071-1082, 2009.

[17] M. N. Uddin and B. Patel, "Loss minimization control of interior permanent magnet synchronous motor drive using adaptive backstepping technique," in Proceedings of the IEEE Industry Applications Society Annual Meeting, pp. 1-7, IEEE, Lake Buena Vista, FL, USA, October 2013.

[18] S. Vaez-Zadeh, M. Zamanifar, and J. Soltani, "Nonlinear efficiency optimization control of IPM synchronous motor drives with online parameter estimation," in Proceedings of the IEEE Power Electronics Specialists Conference, pp. 1-6, IEEE, Jeju, South Korea, June 2006.

[19] Z. Wang, K. Lu, and F. Blaabjerg, "A simple startup strategy based on current regulation for back-emf-based sensorless control of PMSM," IEEE Transactions on Power Electronics, vol. 27, no. 8, pp. 3817-3825, 2012.

[20] M. Fatu, R. Teodorescu, I. Boldea, G. D. Andreescu, and F. Blaabjerg, "I-F starting method with smooth transition to EMF based motion-sensorless vector control of PM synchronous motor/generator," in Proceedings of the IEEE Power Electronics Specialists Conference, pp. 1481-1487, IEEE, Rhodes, Greece, June 2008.

[21] C. Y. Lai, G. D. Feng, K. Mukherjee, V. Loukanov, and N. C. Kar, "Torque ripple modeling and minimization for interior PMSM considering magnetic saturation," IEEE Transactions on Power Electronics, vol. 33, no. 3, pp. 24172429, 2017.

[22] J. H. Jang, S. K. Sul, J. I. Ha, K. Ide, and M. Sawamura, "Sensor-less drive of surface mounted permanent magnet motor by high frequency signal injection based on magnetic saliency," IEEE Transactions on Industry Applications, vol. 39, no. 4, pp. 1031-1039, 2003.

[23] J.-H. Jang, J.-I. Ha, M. Ohto, K. Ide, and S.-K. Sul, “Analysis of permanent-magnet machine for sensorless control based on high-frequency signal injection," IEEE Transactions on Industry Applications, vol. 40, no. 6, pp. 1595-1604, 2004.

[24] C. French and P. Acarnley, "Control of permanent magnet motor drives using a new position estimation technique," IEEE Transactions on Industry Applications, vol. 32, no. 5, pp. 1089-1097, 1996.

[25] T. Senjyu, T. Shimabukuro, and K. Uezato, "Position control of permanent magnet synchronous motors without position and speed sensors," in Proceedings of the IEEE Conference on Industrial Automation and Control Emerging Technology Applications, pp. 759-765, Taipei, Taiwan, May 1995.

[26] R. Li and G. Z. Zhao, "Position sensorless control for PMSM using sliding mode observer and phase-locked loop," in Proceedings of the IEEE 6th International Power Electronics and Motion Control Conference, pp. 1867-1870, IEEE, Wuhan, China, July 2009.

[27] H. Kim, J. Son, and J. Lee, "A high-speed sliding-mode observer for the sensorless speed control of a PMSM," IEEE Transactions on Industrial Electronics, vol. 58, no. 9, pp. 4069-4077, 2011.

[28] S. Bolognani, L. Tubiana, and M. Zigliotto, "Extended kalman filter tuning in sensorless PMSM drives," IEEE Transactions on Industry Applications, vol. 39, no. 6, pp. 1741-1747, 2003.

[29] S. Bolognani, R. Oboe, and M. Zigliotto, "Sensorless fulldigital PMSM drive with EKF estimation of speed and rotor position," IEEE Transactions on Industrial Electronics, vol. 46, no. 1, pp. 184-191, 1999.

[30] J. N. Yang and S. Lin, "Identification of parametric variations of structures based on least squares estimation and adaptive tracking technique," Journal of Engineering Mechanics, vol. 131, no. 3, pp. 290-298, 2005.

[31] J. Zhou, C. Wen, and W. Wang, "Adaptive backstepping control of uncertain systems with unknown input time-delay," Automatica, vol. 45, no. 6, pp. 1415-1422, 2009. 
[32] B. Ding, "Constrained robust model predictive control via parameter-dependent dynamic output feedback," Automatica, vol. 46, no. 9, pp. 1517-1523, 2010.

[33] X. B. Ping and B. C. Ding, "Dynamic output feedback robust model predictive control based on ellipsoidal estimation error bound for quasi-LPV systems," in Proceedings of the 25th Chinese Control and Decision Conference (CCDC), pp. 726731, IEEE, Guiyang, China, May 2013.

[34] D.-f. He, H.-b. Ji, and L. Yu, "Constructive robust model predictive control for constrained non-linear systems with disturbances," IET Control Theory \& Applications, vol. 7, no. 15, pp. 1869-1876, 2013.

[35] P. L. Chapman, S. D. Sudhoff, and C. A. Whitcomb, "Optimal current control strategies for surface-mounted permanentmagnet synchronous machine drives," IEEE Transactions on Energy Conversion, vol. 14, no. 4, pp. 1043-1050, 1999. 